\title{
PARAMETRIC STUDIES ON THE TRIBOLOGICAL BEHAVIOUR OF ALUMINIUM MATRIX HYBRID COMPOSITES
}

\author{
Suresha $\mathbf{S}^{1}$, Sridhara B.K. ${ }^{2}$ \\ ${ }^{1}$ Research Scholar, Department of Mechanical Engineering, The National Institute of Engineering, Mysore. \\ ${ }^{2}$ Department of Mechanical Engineering, The National Institute of Engineering, Mysore. \\ Email : 'surs.mar69@yahoo.com
}

Abstract

Aluminium matrix composites are replacing aluminium alloys and the replacement is mainly attributed to their improved mechanical and tribological properties. Hybrid composites (composites with multiple reinforcements) are of recent application owing to betterment of the mechanical and tribological properties over single reinforced composites. Studies on these composites are limited to a few investigations and all such investigations are on tribological behaviour of hybrid composites with higher percentage of reinforcements. This investigation focuses on the tribological behaviour of aluminium matrix hybrid composites. Wear tests have been carried out on pin-on-disc equipment to study the influence of load, sliding speed and sliding distance on composite specimens with $\%$ reinforcement of $2.5 \%, 5 \%, 7.5 \%$ and $10 \%$ with equal weight percentage of silicon carbide and graphite particulates. Parametric studies based on design of experiments (DOE) techniques indicate that as the \% reinforcement increases wear decreases up to $7.5 \%$ and a tendency to increase beyond $7.5 \%$. Load and sliding distance show a positive influence on wear whereas speed shows a negative influence. A mathematical model to predict the wear of the composite is also presented.

Keywords: Hybrid composites, Design of experiments, Mathematical model.

\section{INTRODUCTION}

The increasing demand for lightweight, inexpensive, energy saving, stiff and strong materials in aircraft, space, defense and automotive applications has stimulated a steadily growing efforts to develop composite materials. Aluminium Matrix Composites (AMCs) are emerging as promising materials in this direction [1, 2]. AMCs reinforced with $\mathrm{SiC}$ particulates are known for higher modulus, strength and wear resistance compared to conventional alloys. C. Garcia et al. have observed that the specific wear rate of AA6061-SiC composites decreases with increase in volume fraction and size of reinforcement [2]. S. Das et al. have discussed on formation of mechanically mixed layer (MML) consisting of debris and smeared and fragmented SiC particles. SiC needles in $M M L$ and in the subsurface region are fragmented in to finer particles thus demonstrating the occurrence of subsurface damage during abrasive wear of LM13-SiC composites [3]. Y Sahin et al. have noticed significant increase in wear resistance up to $10 \%$ addition of $\mathrm{SiC}$ and a stable value between $10-55 \%$ for Al-SiC composites produced by vacuum infiltration [4].

A linear relation between the wear volume and load is the observation of Y.B.Liu et al. for laser processed Al-Gr composites [5]. C. B Lin et al. have investigated Al-Gr composite with $0-6 \mathrm{wt} \% \mathrm{Gr}$ and the results indicate reduced wear rate with increase in particulate content and sliding speed. The dependency of wear rate on hardness of matrix, rate of release of graphite particles and structure of solid lubricating film as well as Al chip clusters are also investigated [6].
Addition of SiC to matrix alloy though improves mechanical strength and wear resistance of composites but results in increased hardness which in turn makes the machining difficult. On the other hand, inclusion of $\mathrm{Gr}$ reduces wear by formation of tribo layer and aids machining due its solid lubrication while the strength of the composite reduces. Thus, advantageous influence of $\mathrm{SiC}$ and $\mathrm{Gr}$ can be enhanced by addition of $\mathrm{SiC}$ as well as $\mathrm{Gr}$ in hybrid composites. The outcome of some investigations on such hybrid composites are briefed in the next few lines.

P. K Rohatgi et al. have reported that the reduction in friction coefficient of $\mathrm{Al}-10 \mathrm{SiC}-6 \mathrm{Gr}$ is due to the combination of increase in bulk mechanical properties as a result of addition of SiC and formation of graphite film [7]. M. L. Ted Guo et al. have observed that wear of Al-10SiC$2-8 \mathrm{Gr}$ increases up to $5 \% \mathrm{Gr}$ because of reduced fracture toughness and then decreases due to formation of thick solid lubricant film which overrides the effect of fracture toughness [8]. A. R Riahi et al. have focused upon the influence of tribo layer of MML containing primarily $\mathrm{Gr}$ on wear of Al-10SiC-4Gr hybrid composites [9]. The investigations of S. Basavarajappa et al. on Al-15SiC-3Gr composites have indicated that the degree of subsurface deformation and thereby the wear rate in graphite composites is less than that of graphite free composites [10]. These investigations emphasize that the use of multiple reinforcements in aluminium matrix hybrid composites yield better tribological properties.

However, efforts are scarce on parametric studies on the tribological behaviour of aluminium matrix hybrid composites. In this context, an attempt is made here to 
study the influence of load, \% reinforcement, sliding speed and sliding distance on the tribological behaviour of Al$\mathrm{SiC}-\mathrm{Gr}$ hybrid composites.

\section{EXPERIMENTS}

Al-SiC-Gr composites required for the investigation are fabricated by stir casting [11]. LM25 is used as the matrix alloy and details of its composition is given in Table 1. Table 2 provides the details of $\mathrm{SiC}$ and $\mathrm{Gr}$ particulates which are used as reinforcements. Table 3 gives the details of hybrid composites. Al-SiC-Gr hybrid composites with combined weight $\%$ reinforcement of $2.5 \%, 5 \%, 7.5 \%$ and $10 \%$ are used. In each of these composite as seen in Table 3, \% reinforcement of each of $\mathrm{SiC}$ and $\mathrm{Gr}$ is equal. The hardness values of these composites are also indicated in the table. There is reduction in hardness with increase in \% reinforcement and this is due to the addition of $\mathrm{Gr}$. The as cast composites are of $10 \mathrm{~mm}$ diameter, $50 \mathrm{~mm}$ length from which wear test specimens of length $35 \mathrm{~mm}$ and $8 \mathrm{~mm}$ diameter are machined. The end of the specimens are polished with abrasive paper of grade 600 and followed by grade 1000. Dry sliding tests are carried out as per ASTM G99-95a test standards on pin-on-disc equipment the disc of which is of EN31 steel with surface roughness, $R_{a} 0.1$. The pins are cleaned with acetone and weighed before and after testing to an accuracy of $0.0001 \mathrm{~g}$ to determine the amount of wear. The sliding end of the pin and the disc surfaces are cleaned with acetone before testing.

Table 1. Chemical composition of the matrix alloy LM25

\begin{tabular}{|c|c|c|c|c|}
\hline Element & $\mathrm{Si}$ & $\mathbf{M g}$ & $\mathrm{Fe}$ & $\mathbf{C u}$ \\
\hline Content \% & 7.1 & 0.3 & 0.3 & $<0.012$ \\
\hline Element & $\mathbf{C r}$ & $\mathbf{Z n}$ & $\mathrm{Ni}$ & $\mathrm{Mn}$ \\
\hline Content \% & 0.004 & 0.002 & 0.01 & 0.28 \\
\hline
\end{tabular}

Table 2. Details of reinforcements

\begin{tabular}{|c|c|c|c|}
\hline Reinforcement & $\begin{array}{c}\text { Hardness } \\
\text { GPa }\end{array}$ & $\begin{array}{c}\text { Grain size } \\
\boldsymbol{\mu m}\end{array}$ & $\begin{array}{c}\text { Density } \\
\mathbf{g} / \mathbf{c m}^{\mathbf{3}}\end{array}$ \\
\hline $\mathrm{SiC}$ & $24.5-29$ & $10-20$ & 3.22 \\
\hline $\mathbf{G r}$ & 0.25 & $70-80$ & $2.09-2.23$ \\
\hline
\end{tabular}

Table 3. Details of Al-SiC-Gr hybrid composites

\begin{tabular}{|c|c|c|c|c|c|}
\hline & \multicolumn{5}{|c|}{ Al-SiC-Gr hybrid composites } \\
\hline $\begin{array}{c}\text { Total \% } \\
\text { reinforcement }\end{array}$ & 0.00 & 2.50 & 5.00 & 7.50 & 10.0 \\
\hline SiC \% & 0.00 & 1.25 & 2.50 & 3.75 & 05.0 \\
\hline Gr \% & 0.00 & 1.25 & 2.50 & 3.75 & 05.0 \\
\hline Hardness, BHN & 67 & 72 & 70 & 68 & 66 \\
\hline
\end{tabular}

Since the objective of this investigation is to carry out the parametric studies, the experiments are designed based on Central Composites Design (CCD) scheme of Design Of Experiments (DOE) [12].

CCD is very effective experimental technique in studies involving large number of factors. A set of experimental design that can look at $\mathrm{K}$ factors in ' $\mathrm{n}$ ' observations with each factor at two levels is called two level factorial design, which can prove good and efficient when a linear relationship prevails between the factors and the response. Three or higher level experiments are mandatory when nonlinear relationship exists, which ends up with increased cost and time of testing. CCD is the most efficient method, alternative to $3^{k}$ or more factorial experimental designs. CCD can be used to study factors at five levels in reduced number of tests [12-15].

Load, \% reinforcement, sliding speed and sliding distance are the factors which influence the tribological behaviour of a composite. Table 4 shows the factors and their levels employed in the experiments. Wear in terms of weight loss is the measured response used to evaluate the tribological behaviour of Al-SiC-Gr hybrid composites. Table 5 provides the experimental plan and the experimental results obtained.

Table 4. Factors and their levels in CCD Experimental Plan

\begin{tabular}{|c|c|c|c|c|c|c|}
\hline \multicolumn{2}{|c|}{$\begin{array}{c}\text { Levels } \\
\text { Factors }\end{array}$} & -2 & -1 & 0 & 1 & 2 \\
\hline $\begin{array}{c}\text { Reinforcement, } \\
\%\end{array}$ & A & 0 & 2.5 & 5 & 7.5 & 10 \\
\hline $\begin{array}{c}\text { Sliding speed, } \\
\mathrm{m} / \mathrm{s}\end{array}$ & B & 0.4 & 0.8 & 1.2 & 1.6 & 2.0 \\
\hline $\begin{array}{c}\text { Load, } \\
\mathrm{N}\end{array}$ & C & 15 & 30 & 45 & 60 & 75 \\
\hline $\begin{array}{c}\text { Sliding distance, } \\
\mathrm{m}\end{array}$ & D & 400 & 800 & 1200 & 1600 & 2000 \\
\hline
\end{tabular}

Table 5. Details of test combinations (tc) in coded values of factors and corresponding experimental results

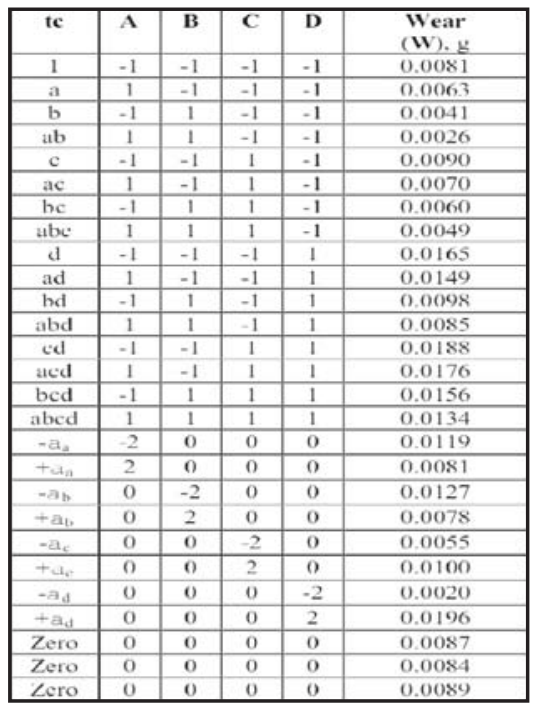




\section{ANALYSIS OF RESULTS}

The experimental results are analyzed with the help of MINITAB14, a statistical analysis software, which is widely used in many fields of engineering research. Results are analyzed by ANOVA with a confidence limit of $95 \%$ or P-value of 0.05 . This implies any factor with Pvalue equal to or less than 0.05 is significant. The significance of a factor can be confirmed by the main effects plot and normal probability plot. The influence of $\%$ reinforcement on wear relative to load, sliding speed and sliding distance are discussed with the help of respective contour plots [13,15].

ANOVA results are given in Table 6. Second and higher order interactions are not considered for ANOVA. The quadratic terms of the factors are included in the analysis in order to incorporate the results of the composite part of CCD which may have curvilinear effect on the response [13]. It can be observed that the $\%$ reinforcement (A), sliding speed $(B)$, load $(C)$ and sliding distance $(D)$ are significant along with the interactions $B C$, $B D$ and $C D$ and the quadratic terms of $A, B$ and $D$ as the $P$ value for these is less than 0.05 . The $\%$ contribution of the factors is calculated by dividing their respective sum of squares value by the total sum of squares and these values are indicated in Table 7. Fig. 1 shows the main effect plot of the effects of factors on wear.

Fig. 2 shows the normal probability plot of standardized effects of factors and their interactions on wear of composites. Apart from the factors $A, B, C$ and $D$, other terms like $B C, B D, C D, A^{*} A, B^{*} B$ and $D^{*} D$ are also significant. The observation indicates that $\%$ reinforcement and sliding speed have negative effect on wear as they are on the left of the normal probability line

\section{Table 6. ANOVA results of wear of Al-SiC-Gr hybrid composites}

\begin{tabular}{|c|c|c|c|c|c|}
\hline \multicolumn{6}{|l|}{$\begin{array}{l}\text { Analysi: } \\
\text { Tests }\end{array}$} \\
\hline Source & $\mathrm{DE}$ & Seq SS & Adj SS & E & P \\
\hline A & 1 & 0.0000172 & $0.00001 / 2$ & 29.17 & 0.000 \\
\hline B & 1 & 0.0000774 & 0.0000774 & 131.51 & 0.000 \\
\hline$A B$ & 1 & 0.0000000 & 0.0000000 & 0.03 & 0.873 \\
\hline c & 1 & 0.0000388 & 0.0000338 & 65.86 & 0.000 \\
\hline AC & 1 & 0.0000000 & 0.0000000 & 0.01 & 0.924 \\
\hline BC & 1 & 0.0000043 & 0.0000043 & 7.32 & 0.019 \\
\hline D & 1 & 0.0004361 & 0.0004361 & 740.91 & 0.000 \\
\hline$A D$ & 1 & 0.0000000 & 0.0000000 & 0.00 & 0.975 \\
\hline BD & 1 & 0.0000037 & 0.0000037 & 5.30 & 0.027 \\
\hline CD & 1 & 0.0000061 & 0.0000061 & 10.41 & 0.007 \\
\hline$A \star A$ & 1 & 0.0000014 & 0.0000037 & 5.26 & 0.028 \\
\hline$B * B$ & 1 & 0.0000033 & 0.0000049 & 8.29 & 0.014 \\
\hline $\mathrm{C} \times \mathrm{C}$ & 1 & 0.0000030 & 0.0000005 & 0.78 & 0.394 \\
\hline$D * D$ & 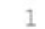 & 0.0000081 & 0.0000081 & 13.74 & 0.003 \\
\hline Error & 12 & 0.0000071 & 0.0000071 & & \\
\hline Tota: & 26 & 0.0006064 & & & \\
\hline
\end{tabular}

Table 7. Percentage contribution of significant factors affecting wear of Al-SiC-Gr hybrid composites
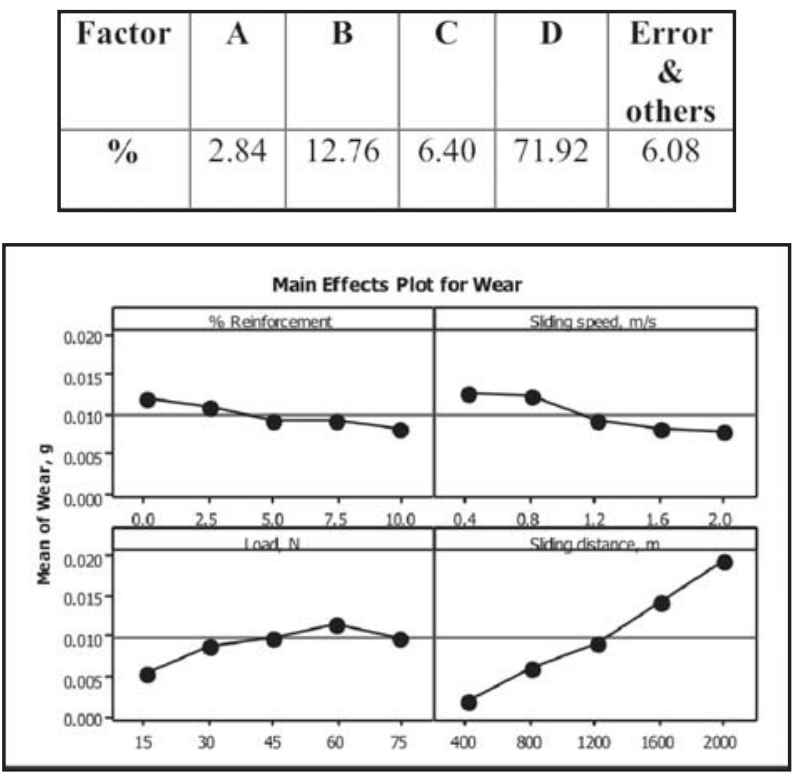

Fig. 1. Main effect plot of effects of factors on wear of composites

indicating any increase of their value from low level to high level results in reduction of wear. Other investigations, based on one factor- at-a-time experiments, have revealed no effect of sliding speed on wear in the range considered in the present work [10]. The effect of other two factors, load and sliding distance is positive on wear as they lie on the right to the line. The effect of sliding distance is more predominant as evident from Fig. 1 and Fig. 2. The effect of load is less than sliding distance as it is close to the line. These are also evident from the values of $\%$ contribution of factors as in Table 7. It can be observed that the value of $\%$ contribution is the highest for sliding distance followed by sliding speed, load and \% reinforcement.

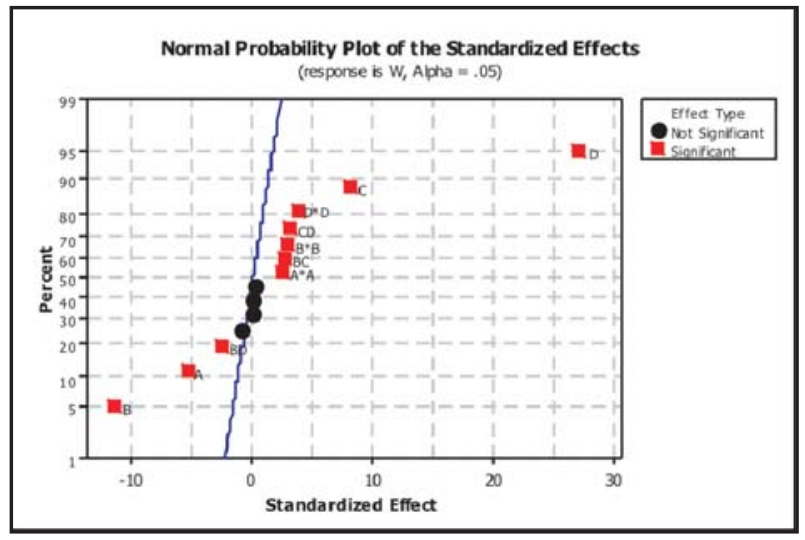

i g 2. No r ra I pr dabi lityp I d of ef feet so f $f$ xt $\sigma$ sa ndt hei ri in $\Theta$ atimso nwe ar of $A-S \in \mathbb{B}$ hybride omp osi tes 
The increase of sliding speed results in formation of a mechanically mixed tribo layer at a faster rate and thus reducing wear by covering more area of contact. Increase in \% reinforcement facilitates availability of more quantity of $\mathrm{SiC}$ and $\mathrm{Gr}$ for the formation of tribo layer. This is evidenced by smear of very fine particles of reinforcements over the disc surface during testing. Any increase of load tries to weaken the tribo layer due to increase of pressure over the tribo layer and consequent reduction of area covered by the layer resulting in increase of wear. Wear increases with sliding distance because of exposure of sliding end of the pin for more duration of time for any values of $\%$ reinforcement, sliding speed and load.

A mathematical model to predict wear is formulated by response surface regression analysis. Response surface and corresponding contour plots give wider insight to understand any problem in general, and to optimize the factors influencing the response in particular $[13,15]$. Table 8 shows the results of response surface regression analysis. The regression model in terms of coded values is represented by equation-1. The adequacy of the model can be checked by normal probability plot of residuals and the plot of residuals v/s fit $[13,15]$. Fig. 3 shows the normal probability plot of residuals. As the points are quite close to the normal probability line, the indication is that residuals are normally distributed and the model is adequate to predict wear. Fig. 4 shows the plot of residual v/s fitted values of the response. It can be seen in the plot that the points are randomly scattered without forming any particular pattern and there by evidencing the model adequacy.

Table 8. Response Surface Regression of Wear, $W$ versus $A, B, C, D$

\begin{tabular}{|l|r|r|c|}
\hline Term & Coef & $T$ & $P$ \\
Constant & 0.008667 & 19.567 & 0.000 \\
A & -0.000846 & -5.401 & 0.000 \\
$B$ & -0.001796 & -11.468 & 0.000 \\
$C$ & 0.001271 & 8.115 & 0.000 \\
$D$ & 0.004263 & 27.220 & 0.000 \\
$A * A$ & 0.000416 & 2.502 & 0.028 \\
$B * B$ & 0.000478 & 2.879 & 0.014 \\
$C * C$ & -0.000147 & -0.884 & 0.394 \\
$D * D$ & 0.000616 & 3.706 & 0.003 \\
$A * B$ & 0.000031 & 0.163 & 0.873 \\
$A * C$ & -0.000019 & -0.098 & 0.924 \\
$A * D$ & 0.000006 & 0.033 & 0.975 \\
$B * C$ & 0.000519 & 2.705 & 0.019 \\
$B * D$ & -0.000481 & -2.509 & 0.027 \\
$C * D$ & 0.000619 & 3.226 & 0.007 \\
\hline
\end{tabular}

$S=0.0007672 \mathrm{R}-\mathrm{Sa}=98.8 \% \mathrm{R}-\mathrm{Sa}(\mathrm{ad} i)=97.5 \%$

The analysis was done using coded units. Estimated Regression Coefficients for Wear, W
$W=0.008667-0.000846 \mathrm{~A}$

$-0.001796 \mathrm{~B}+0.001271 \mathrm{C}+0.004263 \mathrm{D}+0.000416 \mathrm{~A}^{*} \mathrm{~A}$

$+0.000478 B^{*} B+0.000616 D * D+0.000519 B^{*} C$

$-0.000481 B * D+0.000619 C * D$

Here,

$$
\begin{aligned}
& A=(a-5) / 2.5, B=(b-1.2) / 0.4, \\
& C=(c-45) / 15, D=(d-1200) / 400
\end{aligned}
$$

$A, B, C$ and $D$ are coded values and $a, b, c$ and $d$ are actual values of factors.

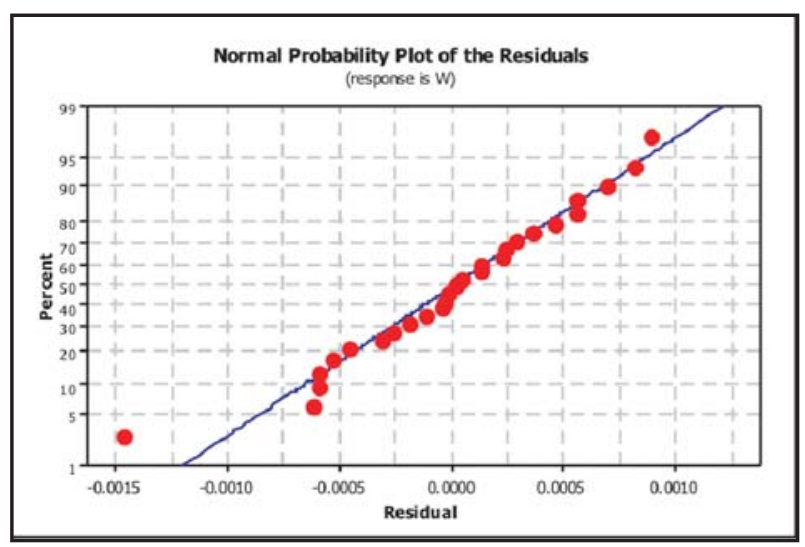

Fig. 3. Normal probability plot of residuals of wear of AlSiC-Gr hybrid composite

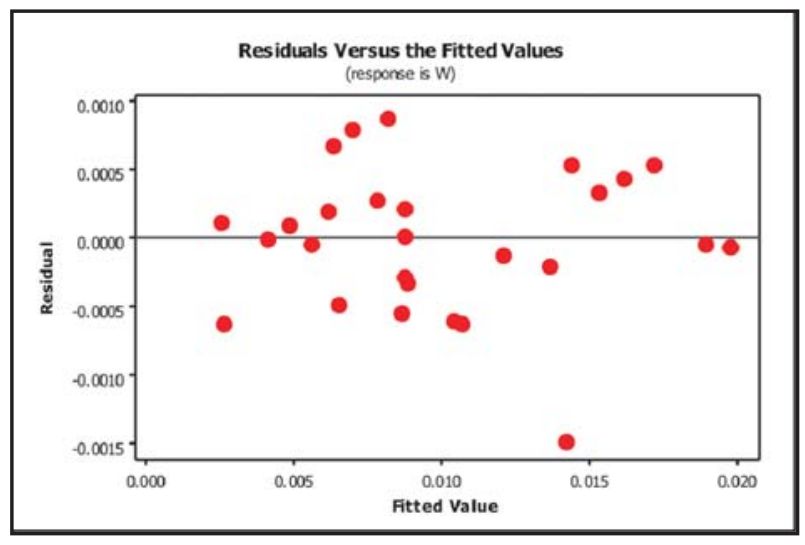

Fig. 4. Plot of residuals v/s fitted values of wear of AlSiC-Gr hybrid composite

\section{DISCUSSIONS}

The experimental results are plotted as contour plots of constant wear. The plot employs a combination of any two factors. \% reinforcement is considered as the common factor and the contour plots are drawn in combination with sliding distance, load and sliding speed. Fig. 5 is the contour plot of wear in terms of \% reinforcement and sliding distance. It is evident from the plot that as the \% reinforcement 
increases, the wear decreases for a particular value of sliding distance. For instance, wear decreases from 0.0122 $\mathrm{g}$ to $0.0098 \mathrm{~g}$ when the $\%$ reinforcement increases to $3.01 \%$ for a sliding distance of $1001 \mathrm{~m}$. The wear further decreases to $0.0085 \mathrm{~g}$ at $\%$ reinforcement of $7.47 \%$ for the same value of sliding distance but increases to $0.0089 \mathrm{~g}$ at \% reinforcement of $9.96 \%$. A similar trend is observed for a sliding distance of $1998 \mathrm{~m}$.

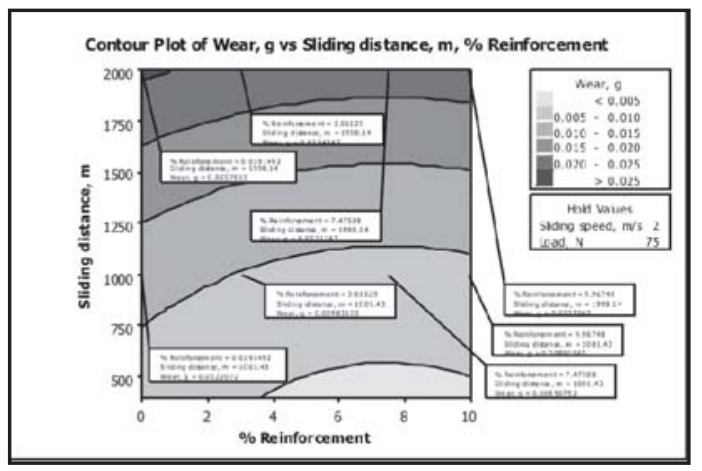

i g 5. Cont aur pl d of ef fect of \% e if $\sigma$ œme nt ands I id rgd i s ance

The contour plot of $\%$ reinforcement in combination with sliding speed for wear of the hybrid composite is shown in Fig. 6. It can be observed that wear decreases continuously from $0.0284 \mathrm{~g}$ at $\%$ reinforcement of $0.01 \%$ to $0.0245 \mathrm{~g}$ at $\%$ reinforcement of $7.63 \%$. It can also be noticed that wear increases to $0.0249 \mathrm{~g}$ at $\%$ reinforcement of $9.97 \%$ for sliding speed of $1.0 \mathrm{~m} / \mathrm{s}$. Similar observation can be made at sliding speed of $1.99 \mathrm{~m} / \mathrm{s}$.

Fig. 7 depicts the contour plot of \% reinforcement in combination with load for wear of composite. It is clear from the plot that wear decreases continuously with increase in \% reinforcement and its value is $0.0145 \mathrm{~g}$ at $\%$ reinforcement of $7.29 \%$. Wear increases to a value of $0.0150 \mathrm{~g}$ at \% reinforcement of $9.98 \%$ for a load of $40 \mathrm{~N}$. Same sort of trend can be noticed at a load of $75 \mathrm{~N}$.

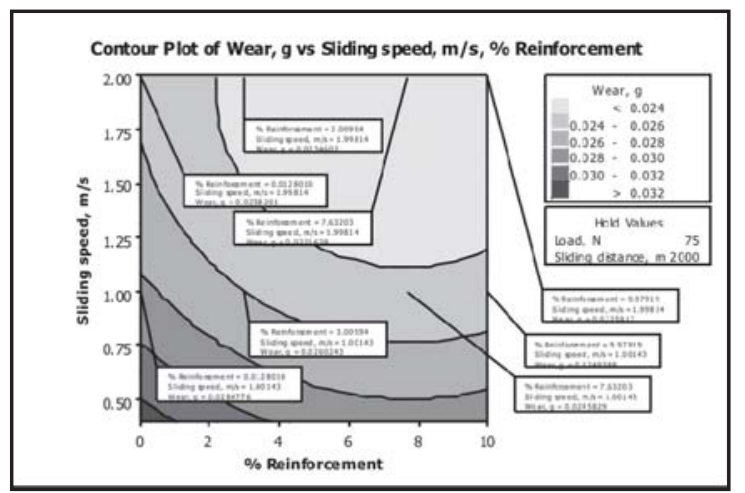

Fig. 6. Contour plot of effect of $\%$ reinforcement and sliding speed on wear of Al-SiC-Gr hybrid composites

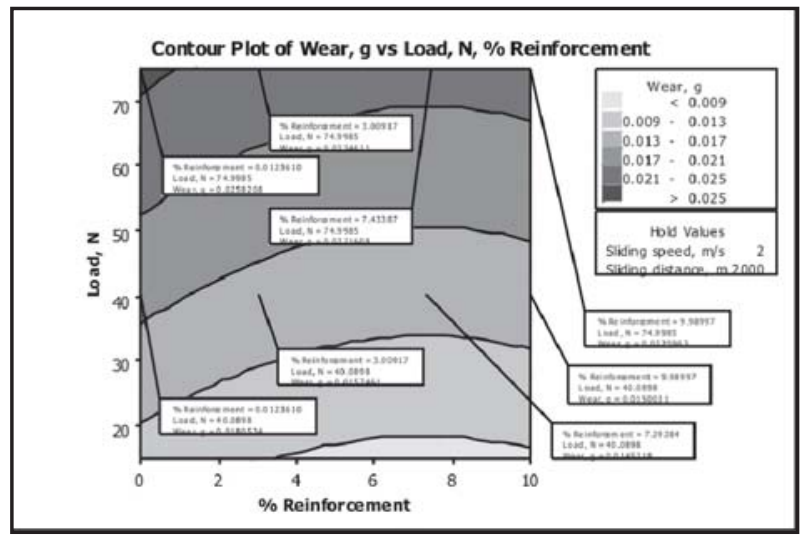

Fig. 7. Contour plot of effect of $\%$ reinforcement and load on wear of Al-SiC-Gr hybrid composites

The contour plots of Fig. 5, Fig. 6 and Fig. 7 show the effect of $\%$ reinforcement on wear for all the values of sliding distance, sliding speed and load within the range considered in the present investigation. It is evident from these plots that, the amount of wear is the least at around $\%$ reinforcement of $7.5 \%$ beyond which it has a tendency to increase up to $\%$ reinforcement of $10 \%$. Thus, it can be concluded that the optimal \% reinforcement is around $7.5 \%$ considering all the factors affecting wear of Al-SiC-Gr hybrid composites.

\section{CONCLUSION}

Experiments are conducted on Al-SiC-Gr hybrid composites with combined reinforcement up to $10 \%$ as using pin-on-disc equipment. Following are the conclusions of the investigation.

- $\quad \%$ reinforcement, sliding speed, load and sliding distance affect the wear. Interactions exist among sliding speed, load and sliding distance.

- Increase of speed reduces wear by supporting mechanically mixed tribo layer and increase of load increases wear by reducing the role of tribo layer. Wear increases with sliding distance and it is the predominant factor affecting wear.

- A mathematical model using response surface regression analysis is formulated and contour plots representing the model have been drawn with \% reinforcement being the common factor in combination with sliding distance, sliding speed and load.

- Analysis of contour plots envisages that, increase in $\%$ reinforcement reduces wear up to around $7.5 \%$ of $\%$ reinforcement and beyond this the wear has a tendency to increase. Thus, the optimal \% 
reinforcement can be around $7.5 \%$ for any value of sliding distance, sliding speed and load within the range considered in the investigation.

\section{REFERENCES}

[1] D.Z. Wang, H.X. Peng, J. Liu and C.K. Yao, 1995, Wear behaviour and microstructural changes of $\mathrm{SiC}_{\mathrm{w}}$-Al composite under unlubricated sliding friction, wear, 184, pp.187-192.

[2] C. Garcia-Cordovilla, J. Narciso and E. Louis, 1996, Abrasive wear resistance of aluminium alloy 1 ceramic particulate composites, Wear, 192, pp. 170177.

[3] S. Das, D.P. Mondal, S. Sawla and S. Dixit, 2002, High Stress Abrasive Wear Mechanism of LM13-SiC Composite under Varying Expeimental Conditions, Metallurgical and Materials Transactions, 33A, pp. 3031-3044.

[4] Y. Sahin, M. Acilar, 2003, Production and properties of SiCp-reinforced aluminium alloy composites, Composites, 34A, pp. 709-718.

[5] Y.B. Liu, J.D. Hu, Z.Y. Cao and P.K. Rohatgi, 1997, Wear resistance of laser processed Al-Si-graphite composites, Wear, 206, pp. 83-86.

[6] C.B. Lin, R.J. Chang and W.P. Weng, 1998, A study on process and tribological behavior of Al alloy/Gr. $(p)$ composite, Wear, 217, pp. 167-174.

[7] P.K. Rohatgi, R. Guo, J.K. Kim, S. Rao, T. Stephenson and T. Waner, 1997, Wear and Friction of Cast Aluminum-SiC-Gr Composites, Proceedings of Materials Solutions' 97 on Wear of Engineering Materials, 15-18 September, Indianapolis, Indiana, pp. 205-211.

[8] M.L. Ted Guo and C.Y.A. Tsao, 2000, Tribological behavior of self-lubricating aluminium/SiC/graphite hybrid composites synthesized by the semi-solid powder-densification method, Composites Science and Technology, 60, pp.65-74.
[9] A. R. Riahi and A.T. Alpas, 2001, The role of tribolayers on the sliding wear behavior of graphitic aluminum matrix composites, Wear, 251, pp. 13961407.

[10] S.Basavarajappa, G. Chandramohan, Arjun Mahadevan, Mukundan Tangavelu, R. Subramanian and P. Gopalakrishnan, 2006, Influence of sliding speed on the dry sliding wear behaviour and the subsurface deformation on hybrid metal matrix composite, Wear.

[11] P.K. Rohatgi, Y. Liu and S. Ray, 2004, Friction and Wear of Metal-Matrix Composites, ASM Hand Book, 18, pp. 801-811.

[12] Thomas B. Barker, 1985, Quality by Experimental Design, Marcel Dekker Inc, New York.

[13] Robert O. Kuehl, 2000, Design of Experiments, Duxbury, U.S.A.

[14] L. Krishnamurthy, B. K. Sridhara and D. Abdul Budan 2007, Comparative Study on the Machinability Aspects of Aluminium Silicon Carbide and Aluminium Graphite Composite, Materials And Manufacturing Processes, 22, pp. 903-908.

[15] Douglas C. Montgomery, 2007, Design and Analysis of Experiments, Wiley India (P) Ltd, New Delhi.

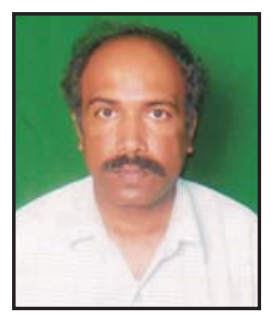

Suresha. $\mathbf{S}$ is a Research Scholar at the Visvesvaraya Technological University, Belgaum, Karnataka. He has a total experience of seventeen years in industry, teaching and research. His area of interest is design engineering. 